Supporting Information for

\title{
Re-Exploring a-Cyano-4-hydroxycinnamic Acid as a Reactive Matrix for Selective Detection of Glutathione via MALDI-MS
}

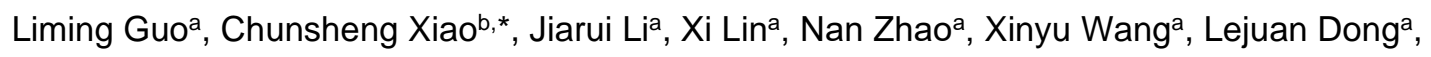

Xinhua Guo a,c,*

a State Key Laboratory of Supramolecular Structure and Materials, College of Chemistry, Jilin University, Changchun 130012, China

${ }^{\mathrm{b}}$ Key Laboratory of Polymer Ecomaterials, Changchun Institute of Applied Chemistry,

Chinese Academy of Sciences, Changchun 130022, China

${ }^{c}$ Key Laboratory for Molecular Enzymology and Engineering of the Ministry of Education,

College of Life Science, Jilin University, Changchun130012, China

Corresponding Authors

E-mail: guoxh@jlu.edu.cn

E-mail: xiaocs@ciac.ac.cn 
Table of contents:

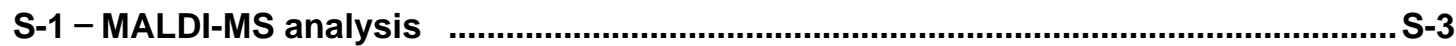

S-2 - Determination of reaction efficiency by LC-MS Analysis ....................................... S-3

S-2 - Figure. S1. Verification of UV-Vis of GSH reaction with CHCA ……..................... S-4

S-3-Figure. S2. Mass spectra for detecting GSH reaction with CHCA under different

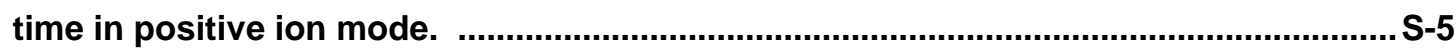

S-4-Figure. S3. Mass spectra for detecting GSH reaction with CHCA under different temperature in positive ion mode. S-5

S-5 - Figure. S4. Mass spectra for detecting GSH reaction with CHCA under different pH in positive ion mode.

S-6 - Figure. S5. The MALDI-TOF-MS spectra of GSH after reaction with different concentration of $\mathrm{CHCA}$

S-7-Figure. S6. Mass spectra for detecting the limit of detection of GSH after reaction with CHCA in positive ion mode. S-7

S-8-Figure. S7. Result of reproducibility experiment. ............................................... S-8

S-9-Figure. S8. The MALDI-TOF-MS spectra of GSH with different matrix. S-8

S-10-Figure. S9. The MALDI-TOF-MS spectra of different samples after reaction with CHCA. S-9

S-11-Table. S1. Reaction effciency of CHCA and GSH. S-9 


\section{MALDI-TOF MS Analysis}

MALDI-TOF MS experiments were performed on an Autoflex speed TOF/TOF mass spectrometry (Bruker, Germany) with a pulsed Nd: YAG laser at a wavelength of 355 $\mathrm{nm}$. Each spectrum was obtained by 500 laser shots and a delayed extraction time of $150 \mathrm{~ns}$ in positive reflector ion mode. The laser energy was kept about $10 \%$ above the threshold of corresponding matrix to obtain the best signal quality with low noise. For the evaluation of the limits of detection (LODs), laser energy was adjusted from $0-100 \%$ above the threshold energy of corresponding matrix ions by variable laser attenuator. Flex Analysis 3.3080 were used to process the data. For MS imaging, the laser spot diameter was focused to a modulated beam profile with a raster width of $150 \mu \mathrm{m}$. The imaging data were recorded using Flex Imaging v3.0. The analyte and matrix solutions were mixed in equal volumes, and then $0.5 \mu \mathrm{L}$ of the resulting mixture solution was spotted on a standard stainless steel target plate and dried at room temperature prior to MALDI-MS analysis. The LOD was defined as the lowest quantity of analyte detected with a $\mathrm{S} / \mathrm{N}$ of $[\mathrm{M}+\mathrm{H}]^{+} \geq 3$ based on MALDI-MS evaluations of serial 10 -fold dilutions of each analyte. All experiments were carried out at least three times to ensure the reproducibility of the experimental data.

\section{Determination of reaction efficiency by LC-MS Analysis}

The peak areas of GSH at their retention time were obtained with a reverse-phase high-performance liquid chromatography (RP-HPLC) combined with electrospray ionization mass spectrometry (ESI-MS). A Zorbax Stablebond Analytical 300SB-C18 column $(2.1 \times 50 \mathrm{~mm}, 1.8 \mu \mathrm{m}$, Agilent Technologies) was used for separation. $50 \%$ Mobile phase I ( $0.1 \%$ formic acid aqueous solution) and $50 \%$ mobile phase II $(0.1 \%$ formic acid acetonitrile solution) were used for elution in 0-5 min. The flow rate was $0.7 \mathrm{~mL} / \mathrm{min}$, and the detection wavelength was 190.0-400.0 $\mathrm{nm}$. Quadrupole time-of-flight ESI-MS (microTOF-Q II, Bruker Daltonics Inc., Germany) was employed in positive ion mode. The peak area ratios of the pure $3 \mathrm{nmol} \mathrm{mL} \mathrm{L}^{-1} \mathrm{GSH}$ and $3 \mathrm{nmol}$ $\mathrm{mL}^{-1} \mathrm{GSH}$ after reacting with $5 \mathrm{mg} \mathrm{mL}^{-1} \mathrm{CHCA}$ were measured by LC-MS and 
used for calculated reaction efficiency (RE). The result was obtained as the average value of three independent measurements.
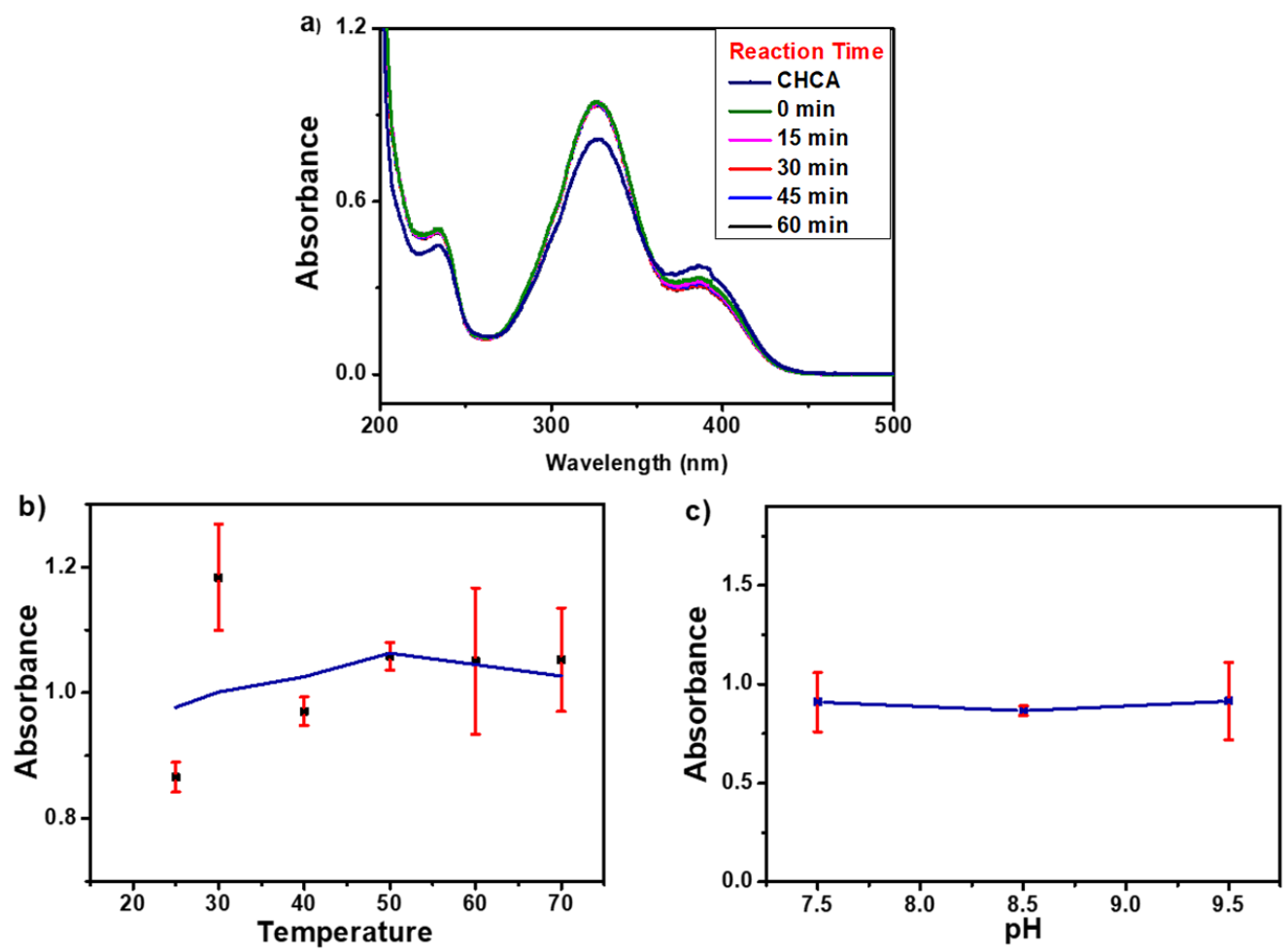

Figure S1. a) Time-dependent UV-Vis absorptions of the CHCA reaction with GSH measued in room temperature. GSH was dissolve in Milli-Q water. The maximum absorption peak was detected at $325 \mathrm{~nm}$ wavelength and optimized reaction time is $30 \mathrm{~min}$; b) The temperature-dependent UV-Vis absorptions at $325 \mathrm{~nm}$ after CHCA reaction with $\mathrm{GSH}$ in pre-configured PBS solutions of $\mathrm{pH} 7.5$ for $30 \mathrm{~min}$; c) The $\mathrm{pH}$-dependent UV-Vis absorptions at $325 \mathrm{~nm}$ after $\mathrm{CHCA}$ with $\mathrm{GSH}$ reacted for $30 \mathrm{~min}$ at $50{ }^{\circ} \mathrm{C}$ in pre-configured PBS solutions at $\mathrm{pH}$ of $7.5,8.5$ and 9.5 respectively. The CHCA was prepared in $50 \%$ ACN/0.1\% TFA (v/v) (TA50) solution at a concentration of $5 \mathrm{mg} \mathrm{mL}^{-1} .500 \mu \mathrm{L}$ of analyte and $500 \mu \mathrm{L}$ of matrix solution were pre-reaction at room temperature. GSH final concentration is $10 \mathrm{nmol} \mu \mathrm{L}^{-1}$. 

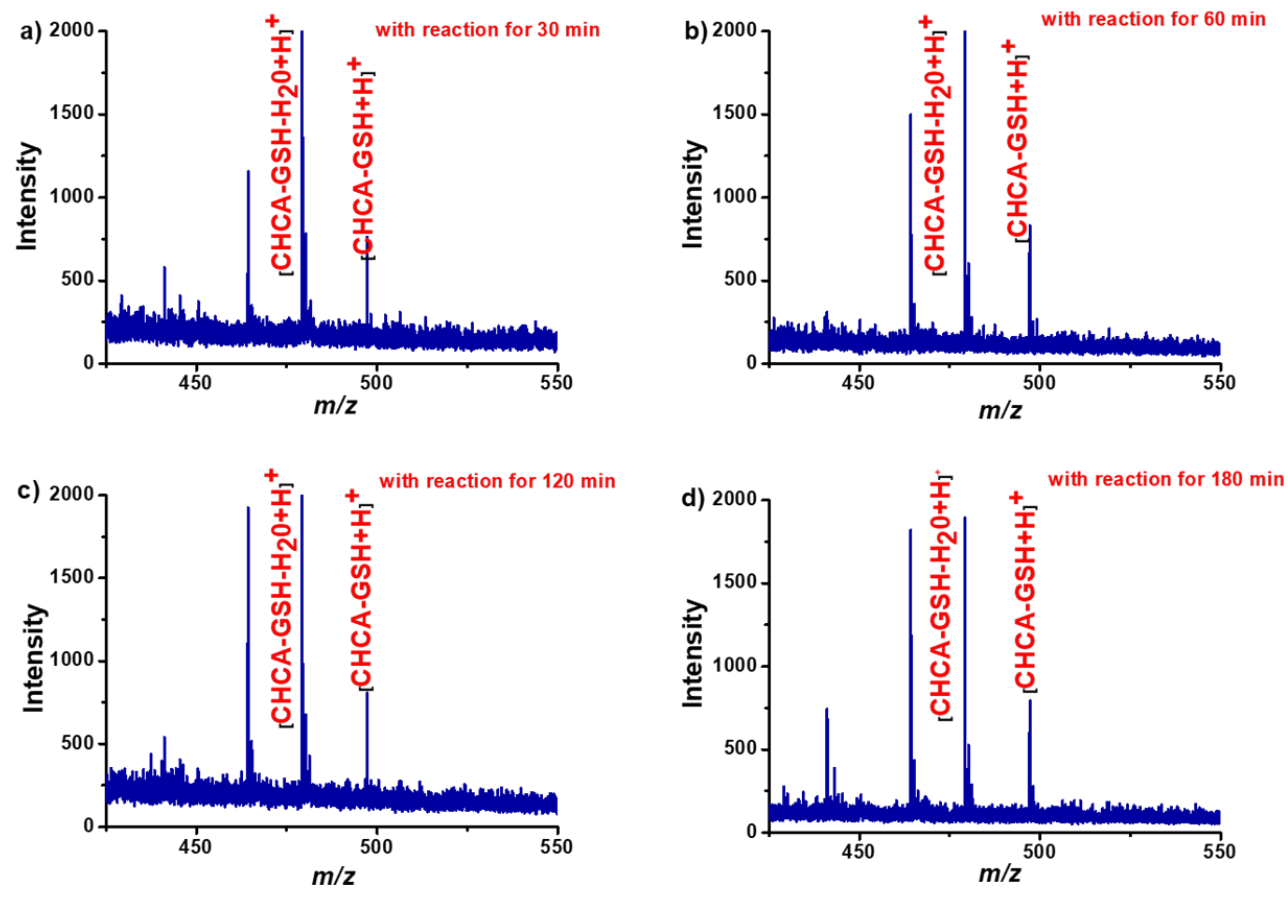

Figure S2. The MALDI-TOF-MS spectra of GSH by using CHCA as a reactive matrix by varying incubation time at room temperature a) $30 \mathrm{~min}$, b) $60 \mathrm{~min}$, c) $120 \mathrm{~min}$ and d) $180 \mathrm{~min}$. The concentration of $\mathrm{GSH}$ was $10 \mathrm{nmol} \mu \mathrm{L}^{-1}$. [GSH $\left.+\mathrm{H}^{+}\right]^{+}(\mathrm{m} / \mathrm{z} 308.1)$, [CHCA-GSH $-\mathrm{H}_{2} \mathrm{O}$ $\left.+\mathrm{H}^{+}\right]^{+}\left(\mathrm{m} / \mathrm{z} \text { 479.1), [CHCA-GSH +H } \mathrm{H}^{+}\right]^{+}(\mathrm{m} / \mathrm{z} 497.1)$ 

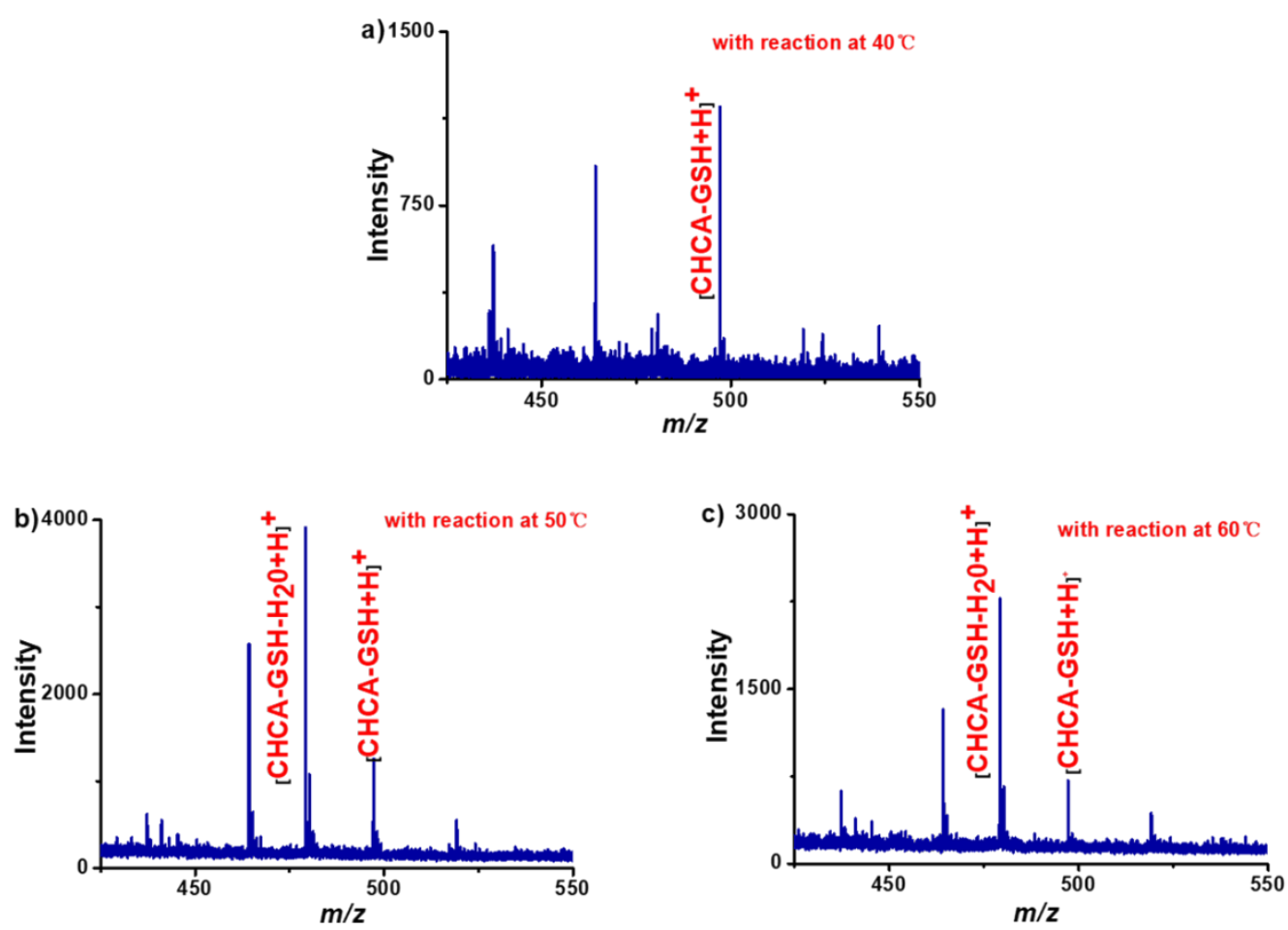

Figure S3. The MALDI-TOF-MS spectra of GSH after reaction with CHCA at $\mathrm{pH} 7.5$ for 30 min at different reaction temperature; a) $40{ }^{\circ} \mathrm{C}$, b) $50{ }^{\circ} \mathrm{C}$ and c) $60{ }^{\circ} \mathrm{C}$. The concentration of GSH was at $10 \mathrm{nmol} \mu \mathrm{L}^{-1}$. [GSH $\left.+\mathrm{H}^{+}\right]^{+}\left(\mathrm{m} / \mathrm{z} \text { 308.1), [CHCA-GSH }-\mathrm{H}_{2} \mathrm{O}+\mathrm{H}^{+}\right]^{+}(\mathrm{m} / \mathrm{z} 479.1)$, $\left[\mathrm{CHCA}-\mathrm{GSH}+\mathrm{H}^{+}\right]^{+}(\mathrm{m} / \mathrm{z} 497.1)$ 

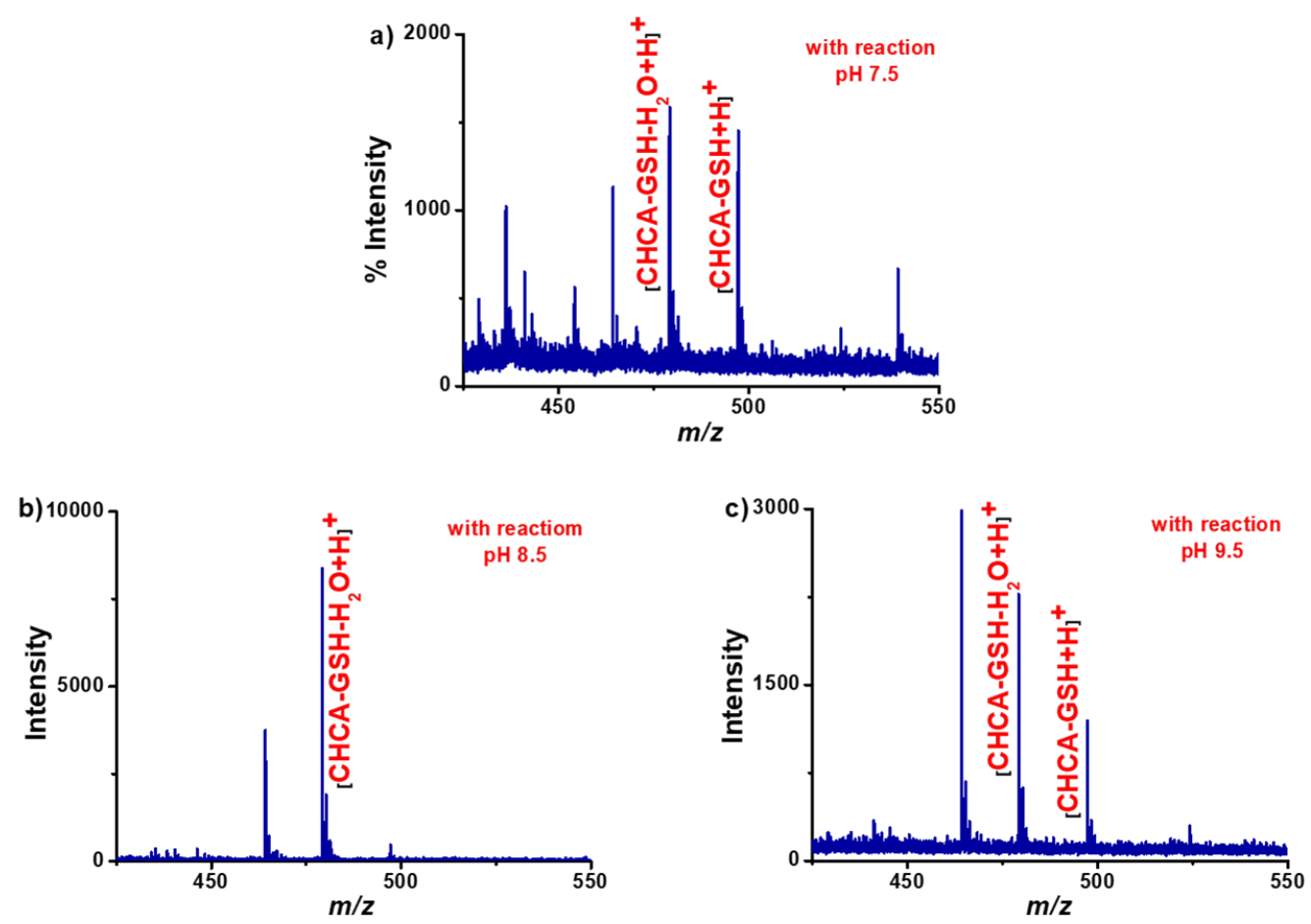

Figure S4. The MALDI-TOF-MS spectra of GSH after reaction with CHCA for $30 \mathrm{~min}$ at $50{ }^{\circ} \mathrm{C}$ different $\mathrm{pH}$; a) 7.5 , b) 8.5 , c) 9.5. The concentration of $\mathrm{GSH}$ was at $10 \mathrm{nmol} \mu \mathrm{L}^{-1}$. [GSH + $\left.\mathrm{H}^{+}\right]^{+}\left(\mathrm{m} / \mathrm{z} \text { 308.1), [CHCA-GSH }-\mathrm{H}_{2} \mathrm{O}+\mathrm{H}^{+}\right]^{+}(\mathrm{m} / \mathrm{z} 479.1),\left[\mathrm{CHCA}-\mathrm{GSH}+\mathrm{H}^{+}\right]^{+}(\mathrm{m} / \mathrm{z} 497.1)$ 

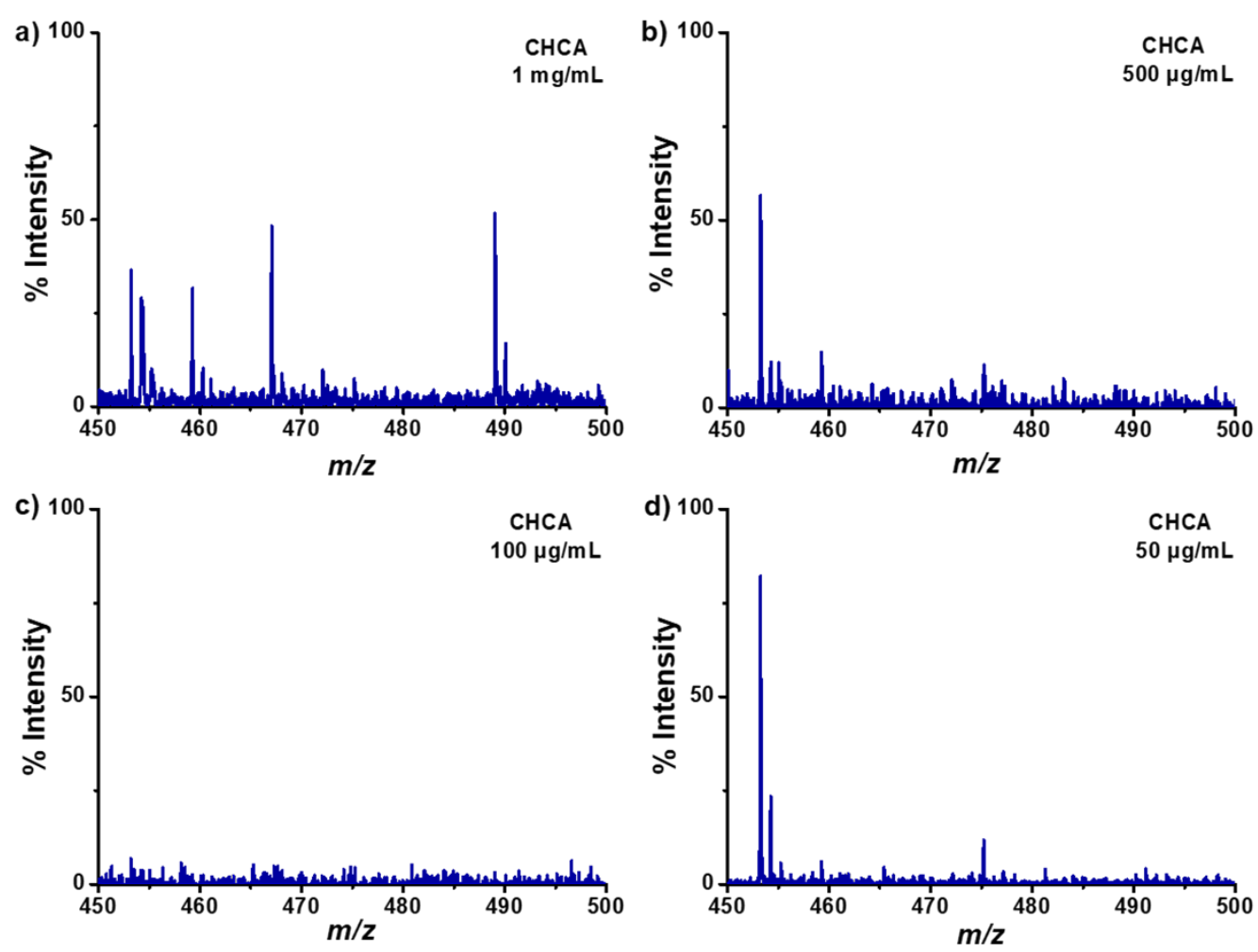

Figure S5. The MALDI-TOF-MS spectra of GSH after reaction with different concentration of CHCA for 30 min at $50{ }^{\circ} \mathrm{C} \quad$; a) CHCA $1 \mathrm{mg} \mathrm{mL}^{-1}$, b) CHCA $500 \mu \mathrm{g} \mathrm{mL}-1$, c) CHCA $100 \mu \mathrm{g}$ $\mathrm{mL}^{-1}$, d) CHCA $50 \mu \mathrm{g} \mathrm{mL}^{-1}$. The concentration of $\mathrm{GSH}$ was at $10 \mathrm{nmol} \mu \mathrm{L}^{-1}$. [GSH $\left.+\mathrm{H}^{+}\right]^{+}(\mathrm{m} / \mathrm{z}$ 308.1), [CHCA-GSH $\left.-\mathrm{H}_{2} \mathrm{O}+\mathrm{H}^{+}\right]^{+}(\mathrm{m} / \mathrm{z} 479.1), \quad\left[\mathrm{CHCA}-\mathrm{GSH}+\mathrm{H}^{+}\right]^{+}(\mathrm{m} / \mathrm{z} 497.1)$ 


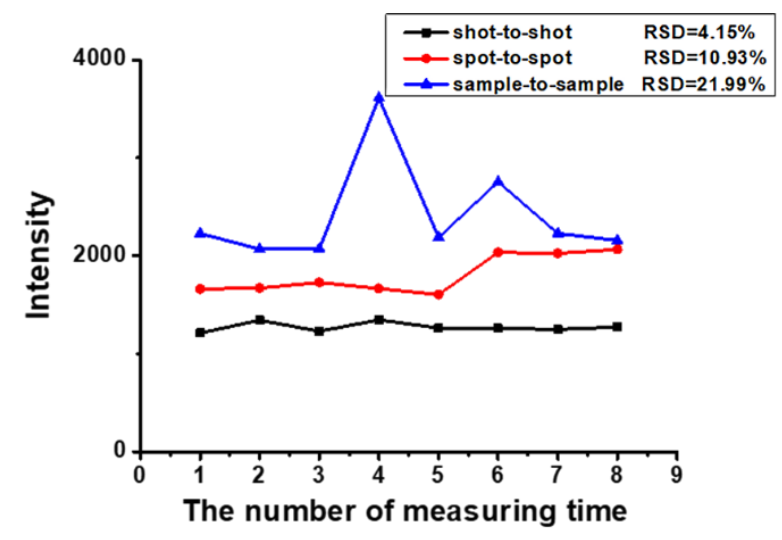

Figure. S6. The [CHCA-GSH $\left.-\mathrm{H}_{2} \mathrm{O}+\mathrm{H}^{+}\right]^{+}$peak intensity of $\mathrm{GSH}$ at $10 \mathrm{nmol} \mu \mathrm{L}^{-1}$ after reacted with $5 \mathrm{mg} \mathrm{mL}^{-1} \mathrm{CHCA}$ in positive ion mode in three different experiments shot-to-shot (black) $(\mathrm{RSD}=4.15 \%)$, sample-to-sample (blue) $(\mathrm{RSD}=21.99 \%)$ and spot-to-spot (red) $(\mathrm{RSD}=$ $10.93 \%)$.
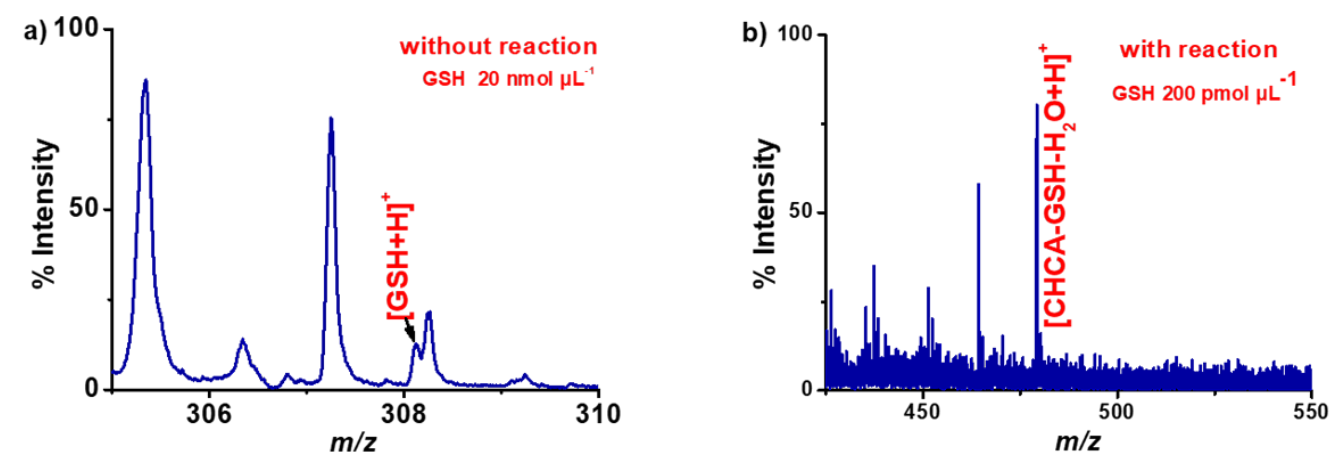

Figure S7. The MALDI-TOF-MS spectra of GSH a) by using CHCA as a common matrix and b) by using $\mathrm{CHCA}$ as a reactive matrix. The concentration of GSH was marked in the Figure. $\left[\mathrm{GSH}+\mathrm{H}^{+}\right]^{+}(\mathrm{m} / \mathrm{z} 308.1),\left[\mathrm{CHCA}-\mathrm{GSH}-\mathrm{H}_{2} \mathrm{O}+\mathrm{H}^{+}\right]^{+}(\mathrm{m} / \mathrm{z} 479.1)$ 

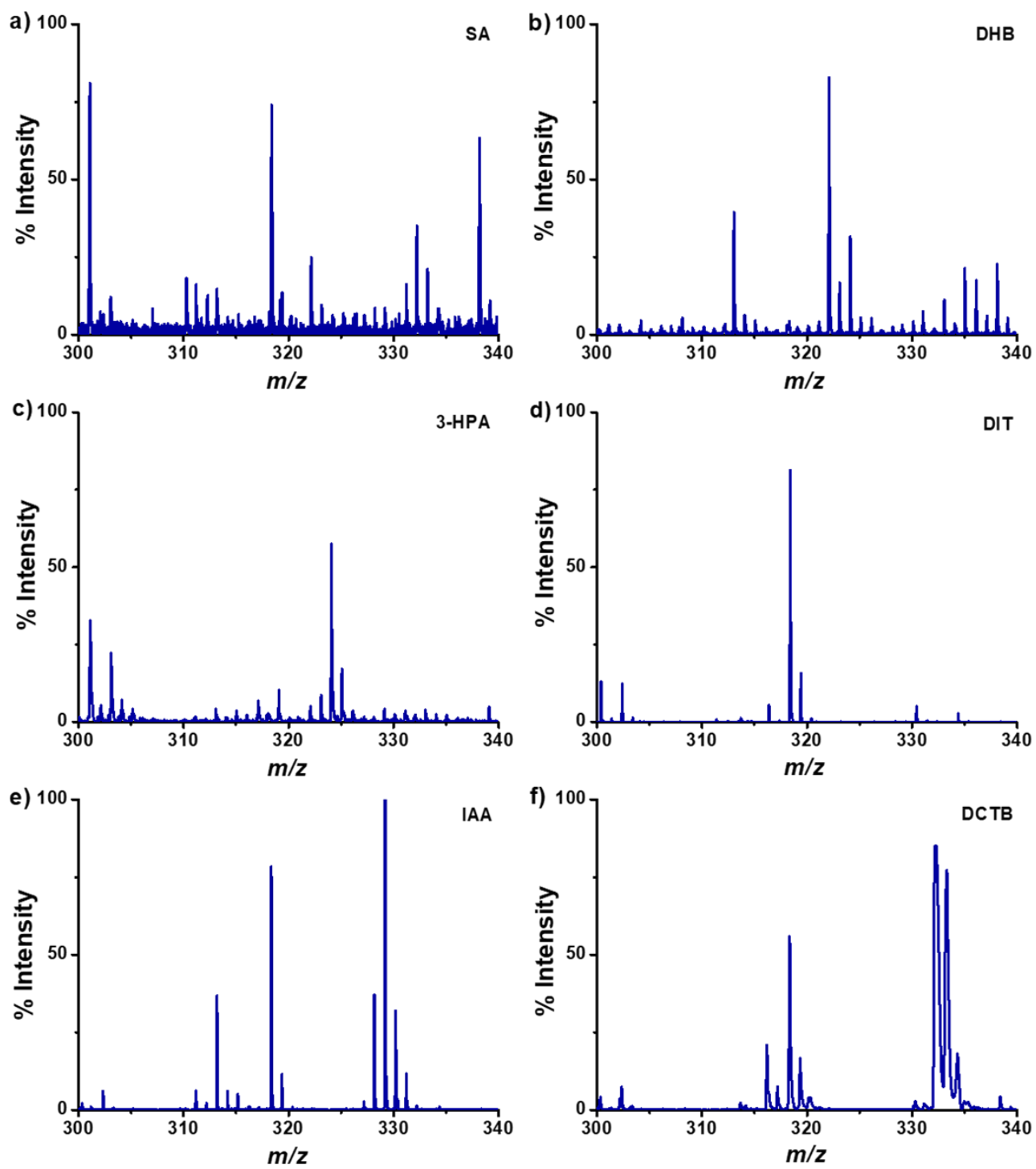

Figure S8. The MALDI-TOF-MS spectra of GSH with different matrix; a) SA, b) DHB, c) 3-HPA, d) DIT, e) IAA, f) DCTB. The concentration of GSH was at $200 \mathrm{pmol} \mu \mathrm{L}^{-1}$. [GSH $\left.+\mathrm{H}^{+}\right]^{+}(\mathrm{m} / \mathrm{z}$ $308.1)$. 

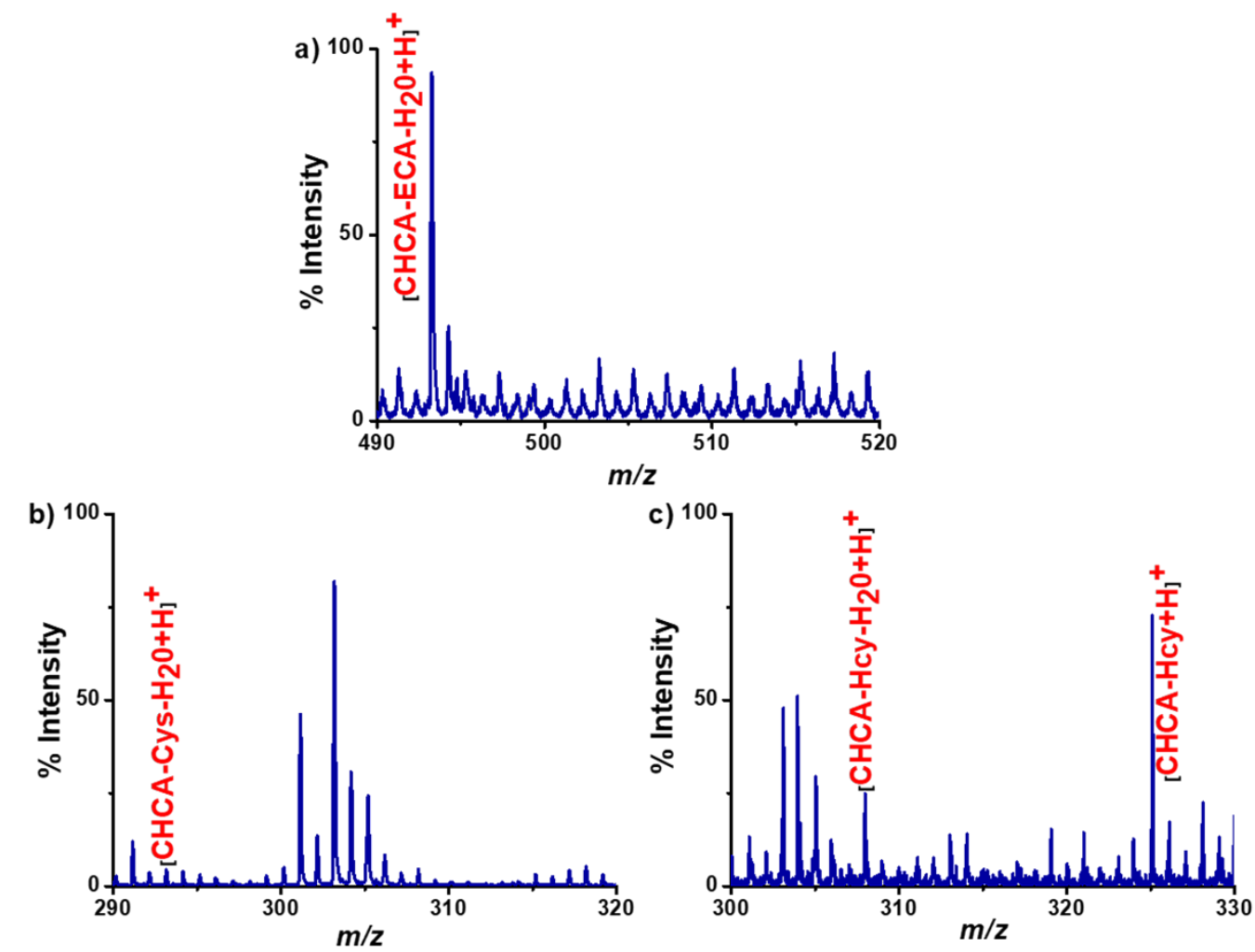

Figure S9. The MALDI-TOF-MS spectra of $5 \mathrm{mg} \mathrm{mL}^{-1} \mathrm{CHCA}$ reaction with a) ECA, b) Cys, c) Hcy for $30 \mathrm{~min}$ at $50{ }^{\circ} \mathrm{C}$. The concentration of each sample is at $10 \mathrm{nmol} \mu \mathrm{L}^{-1}$. [CHCA-ECA $\left.-\mathrm{H}_{2} \mathrm{O}+\mathrm{H}^{+}\right]^{+}\left(\mathrm{m} / \mathrm{z} \text { 493.1), [CHCA-ECA }+\mathrm{H}^{+}\right]^{+}\left(\mathrm{m} / \mathrm{z} \text { 511.1), [CHCA-Cys }-\mathrm{H}_{2} \mathrm{O}+\mathrm{H}^{+}\right]^{+}(\mathrm{m} / \mathrm{z} 293.1)$, [CHCA-Cys $\left.+\mathrm{H}^{+}\right]^{+}(\mathrm{m} / \mathrm{z} 311.1),{ }^{2}$ CHCA-Hcy $\left.-\mathrm{H}_{2} \mathrm{O}+\mathrm{H}^{+}\right]^{+}(\mathrm{m} / \mathrm{z} 307.1), \quad\left[\mathrm{CHCA}-\mathrm{Hcy}+\mathrm{H}^{+}\right]^{+} \quad(\mathrm{m} / \mathrm{z}$ 325.1).

Table S1. Reaction efficiency of CHCA and GSH

\begin{tabular}{ccccc}
\hline Sample & $\begin{array}{c}\text { GSH } \\
\text { peak area } \\
\text { without reaction }\end{array}$ & $\begin{array}{c}\text { GSH } \\
\text { peak area } \\
\text { with reaction }\end{array}$ & $\begin{array}{c}\text { a Reaction } \\
\text { efficiency (\%) }\end{array}$ & $\begin{array}{c}\text { b Average } \\
\text { reaction } \\
\text { efficiency (\%) }\end{array}$ \\
\hline 1 & 690595 & 511533 & $25.93 \%$ & \\
2 & 691063 & 530301 & $23.26 \%$ & $23.14 \pm 2.85 \%$ \\
3 & 691063 & 551234 & $20.23 \%$ & \\
\hline
\end{tabular}

a Reaction efficiency $(\%)=\frac{\text { GSH peak area without reaction }- \text { GSH peak area with reaction }}{\text { GSH peak area without reaction }} \times 100 \%$

${ }^{b}$ Average reaction efficiency $(\%)=\frac{\text { Reaction efficiency }_{n 1}+\cdots+\text { Reaction efficiency }_{n n}}{n n} \times 100 \%$ 